\section{Medal for Professor Davenport}

At the Royal College of Surgeons of Edinburgh's Diploma Ceremony in November, Professor Elizabeth S. Davenport received the Faculty of Dental Surgery Medal 2019 for significant contributions to the Dental Faculty, College and dentistry as a whole. Professor Davenport (pictured, centre) holds the post of Emerita Professor Dental Education of the Barts and London School of Medicine and Dentistry at Queen Mary University, London.

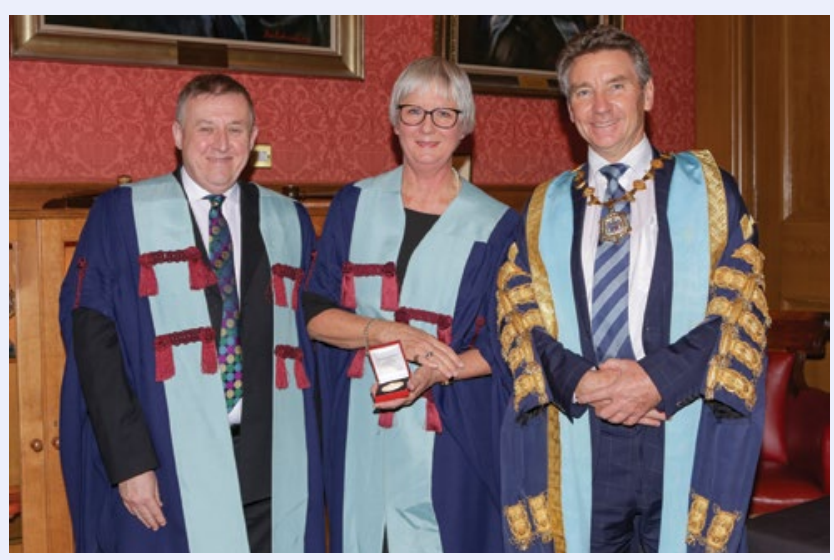

\section{From the museum archive}
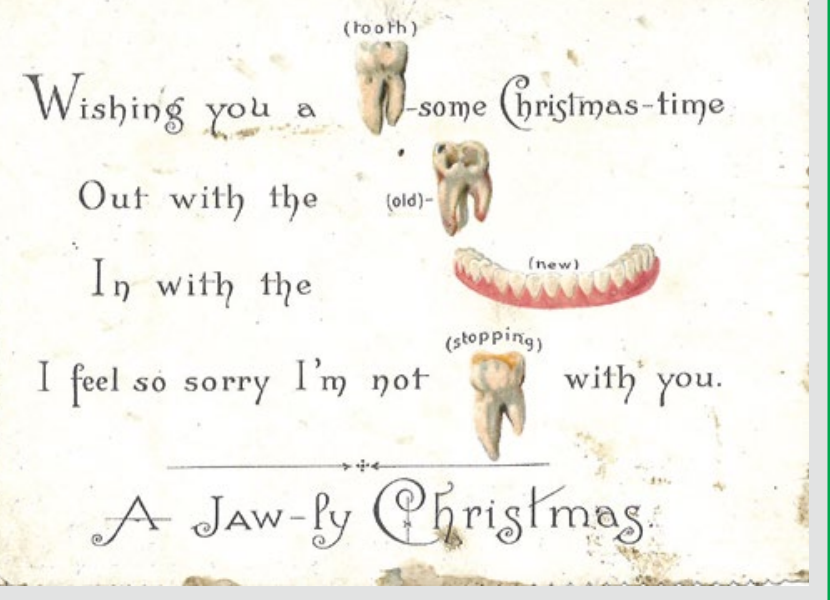

This Christmas message was sent by a dental practice around 1900. Thank you to Rachel Bairsto at the BDA Museum for sharing it with the Journal this December, 119 years later.

\section{Gum disease doubles stroke risk}

A new study conducted by a team in Brazil has found that people with periodontal disease are around twice as likely to have a stroke. ${ }^{1}$ Researchers have discovered that when the gums bleed and become inflamed, it leads to changes in how blood and oxygen flows to the brain.

The new study, which also examined more than 2,000 previous studies into the area, supports previous studies that have linked a heightened stroke risk with gum disease.

\section{Reference}

1. Fagundes N C F, Almeida A P C P S C, Vilhena K F B, Magno M B, Maia L C, Lima R R. Periodontitis as a risk factor for stroke: a systematic review and meta-analysis. Vascular Health and Risk Management 2019; 15: 519-532. Available at: https:// www.dovepress.com/periodontitis-as-a-risk-factor-for-stroke-a-systematic-review-and-meta-peer-reviewed-article-VHRM (accessed December 2019).

\section{BDA AGMs}

The East Midland BDA Branch is holding its AGM and Branch Council meeting on Wednesday 8 January 2020 at Hilton East Midlands Airport, Junction 24, M1, Derby Road, Derby, DE74 2YZ. It will start at $7.30 \mathrm{pm}$ and finish at $9 \mathrm{pm}$. If you are able to attend, please email branchsectionevents@bda.org with your name and GDC number.

The Middlesex and Hertfordshire BDA Branch AGM is taking place on Thursday 13 February 2020 at Holiday Inn Elstree Hotel, Barnet Bypass, Borehamwood, Hertfordshire, WD6 5PU (M25 Junction 23). It will start at $7 \mathrm{pm}$ prompt. To book please visit www.bda.org/bse. 